\title{
Considerações histórico-filosóficas sobre racismo, mestiçagem e biopolítica
}

\author{
PEDRO FORNACIARI GRABOIS *
}

* Doutorando do Programa de Pós-Graduação em Filosofia da Universidade do Estado do Rio de Janeiro (PPGFIL-UERJ)

Professor do Instituto Federal de Educação, Ciência e Tecnologia do Rio de Janeiro (IFRJ) pedro.grabois@ifrj.edu.br

\begin{abstract}
RESUMO Este trabalho investiga o racismo moderno brasileiro, analisando a questão da "mestiçagem" a partir de perspectivas histórico-filosóficas contemporâneas ligadas à noção de biopolítica. A hipótese que exploro é a de que o discurso da mestiçagem no Brasil teria funcionado historicamente como estratégia biopolítica racista, uma vez que foi produzido e mantido nos limites de um horizonte racial branco.
\end{abstract}

PALAVRAS-ChAVE biopolítica, mestiçagem, racismo, raça, branquitude

RÉSUMÉ Ce travail essaye de comprendre le racisme moderne brésilien, en analysant la question du «métissage » à partir de quelques perspectives historico-philosophiques contemporaines liées à la notion de biopolitique. On défend l'hypothèse selon laquelle le discours du métissage au Brésil aurait fonctionné historiquement comme une stratégie biopolitique raciste, une fois qu'il a été produit et maintenu dans les limites d'un horizon racial blanc.

мотS-CLÉs biopolitique, métissage, racisme, race, blanchité

\section{INTRODUÇÃO}

Este trabalho tem o objetivo de contribuir com a compreensão do racismo moderno brasileiro, analisando a questão da "mestiçagem" a partir de perspectivas histórico-filosóficas contemporâneas ligadas à noção de biopolítica. A hipótese que defendemos é a de que, no Brasil, a mestiçagem teria funcionado, em última instância, como estratégia biopolítica explícita de “melhoramento da raça”, com vistas à supressão progressiva do elemento negro e indígena da população e à imposição da branquitude como modelo dominante. Tal hipótese segue na esteira dos apontamentos feitos por movimentos negros brasileiros a partir dos anos 1970. Neste sentido, a obra, de Ab- 
dias do Nascimento, O genocídio do negro brasileiro: processo de um racismo mascarado (1978) é uma contribuição imprescindível. Para uma aproximação biopolítica do tema da mestiçagem, em primeiro lugar, apresento um breve comentário situando a questão racial como uma questão biopolítica para, em seguida, apresentar a mestiçagem em suas transformações históricas.

\section{QUESTÕES BIOPOLÍTICAS: RECORTES POPULACIONAIS RACIALIZADOS}

A biopolítica e o biopoder aparecem no pensamento de Foucault como conceitos operatórios que tentam indicar a maneira pela qual as práticas políticas modernas e contemporâneas tomam a vida dos indivíduos e das populações como objeto de uma intervenção cada vez mais mensurável e calculável. Fazer política passa a significar administrar a vida das populações que habitam uma determinada localidade. Esta gestão da vida se dá a partir da produção de saberes sobre os sujeitos governados. Neste sentido, a estatística e os saberes médicos são imprescindíveis. As taxas que envolvem a saúda de uma população (natalidade, mortalidade, morbidade, expectativa de vida, etc.) tornam-se, portanto, imprescindíveis para as intervenções estatais. Questões de higiene pública e intervenções sanitárias sobre a cidade tornam-se elementos fundamentais no século XIX. Controlar a circulação de pessoas e a transmissão de doenças são imperativos dessa nova ordem política. Falar em biopolítica é, em minha perspectiva, um esforço de desnaturalizar tais práticas discursivas e não-discursivas, relendo aquilo que elas mesmas já dizem em seus registros e documentos muitas vezes detalhistas. Na hipótese elaborada por Foucault na década de 1970 no curso Em defesa da sociedade e no livro A vontade de saber, o racismo funcionaria como tecnologia de poder capaz de separar um grupo populacional específico no interior de uma população mais ampla. Este grupo recortado no interior da população seria visto como inimigo interno, ameaça à integridade, à saúde e à vida desse todo populacional. Assim, o nazismo ou mesmo as práticas de defesa social empregadas no tratamento dado aos criminosos foram apontados por Foucault como exemplos paradigmáticos da presença desse racismo de Estado. O racismo que ocupa o centro da análise de Foucault não é exatamente um racismo étnico, mas antes um "racismo contra o anormal", que pode ou não se entrecruzar com o racismo étnico. De todo modo, o racismo de Estado se apresenta, na perspectiva foucaultiana, como estratégia de produção de morte no interior de uma sociedade do biopoder, isto é, como elemento que compre- 
ende a gestão da morte como parte da gestão da vida. É em nome da vida de uns que se tira - ou se expõe à morte - a vida de outros.

Ann Laura Stoler (2013) resume o significado de biopoder em Foucault como a inscrição de um poder disciplinar que tem por alvo o indivíduo no seio de um poder de Estado, que toma, por sua vez, o corpo social como objeto. Trata-se, portanto, da articulação entre corpo individual e corpo político através da microgestão do primeiro, da macrovigilância do segundo, bem como dos circuitos de controle que existem entre os dois. Segundo Stoler, esta é a condição de possibilidade da existência do racismo sob sua forma atual e tal caracterização do (bio)poder faz sentido no contexto colonial, elemento ausente nos cursos e escritos foucaultianos.

Numa releitura biopolítica de Hannah Arendt, Agamben (2010) menciona a questão do "nascimento" relacionando-a à questão da nação, do pertencimento nacional. A “crise dos refugiados”, que marca o mundo desde meados do século XX, seria assim lida como a colocação em xeque da maneira pela qual os Estados modernos gerem a vida baseando os direitos de cidadania no pertencimento "natural” (de nascença) a um território. Hoje, o debate sobre os direitos sexuais e reprodutivos envolve não apenas a questão do direito ao aborto (desde a despenalização até a oferta pública do serviço) e a maiores autonomia e controle das mulheres sobre o próprio corpo, mas conjuga também reivindicações sobre o direito de nascer em condições dignas - muitas vezes chamadas de condições "humanizadas" do parto. Ao apontar o racismo na saúde, indicado a partir de relatos e de mensurações estatísticas em termos sociais e raciais das desigualdades nas condições de nascer, viver, adoecer e morrer, os movimentos sociais negros brasileiros trouxeram a reflexão biopolítica sobre o nascimento de volta para o interior de um mesmo território nacional. Raça e racismo se apresentam, neste sentido, como questões estruturalmente ligadas ao funcionamento do Estado moderno brasileiro.

No debate público ${ }^{1}$, a questão dos pertencimentos raciais é atravessada constantemente por um argumento de suspeita - ele mesmo colocado em suspeição aqui -, segundo o qual, no Brasil, seria impossível definir quem é negro e quem é branco. Ou

1 Para mais informações sobre esse debate, ver, por exemplo, o livro organizado por Monteiro e Sansone (2014), intitulado Etnicidade na América Latina: um debate sobre raça, saúde e direitos reprodutivos. 
melhor dizendo, segundo essa narrativa, o binarismo negro/branco não daria conta de compreender a diversidade de classificações raciais que marcam historicamente o país, uma vez que a mestiçagem ou miscigenação - ou ainda mistura ou cruzamento racial - seria o elemento marcante de nossa constituição populacional. Em minha perspectiva, tal argumentação, que gira em torno da afirmação do Brasil como "nação mestiça” ou de que "somos todos mestiços”, acaba por inviabilizar o reconhecimento de um fenômeno como o racismo institucional no acesso a diferentes serviços e recursos da sociedade ${ }^{2}$. O problema de tais narrativas da miscigenação é que tomam-na por um dado natural, sem entender que ela mesma é efeito de uma série de investimentos discursivos, políticos e sociais ${ }^{3}$.

\section{MESTIÇAGEM COMO ESTRATÉGIA BIOPOLÍTICA E SUAS TRANSFORMAÇÕES HISTÓRICAS}

Um dos desafios em repensar a história e a política brasileira em termos raciais está no fato de que, em diversos momentos, o racismo não aparece de maneira explícita, mas codificado em registros mais sutis. Como afirma Chalhoub (1996, p. 94), ao analisar a questão da saúde pública no século XIX: “O verdadeiro desafio para o estudioso da ideologia racial no Brasil, entretanto, é reconhecer que a aparente ausência de uma terminologia racial elaborada não significa a ausência de significados raciais”. Este cuidado e reconhecimento são fundamentais diante dos usos oficiais que se construíram em torno da "miscigenação".

Cocco e Negri (2005) apontam uma periodização bastante ampla acerca do fenômeno da miscigenação como estratégia biopolítica de controle da população. Eles afirmam que já a partir dos séculos XV e XVI, as relações sociais estabelecidas pela colonização europeia procuram aniquilar sistematicamente o corpo social nativo através de dois mecanismos: o extermínio puro e simples (pela espada ou pela contaminação) e a mestiçagem destinada a suprir a insuficiência demográfica dos fluxos imigratórios de que a península ibérica era capaz. A mestiçagem seria, então, parte integrante dos processos

2 Diante da estratégia discursiva do "apelo à mestiçagem” para dificultar a possibilidade de apreensão da diferença entre negros e brancos no Brasil e compará-la eficazmente à questão, por exemplo, da estratificação social, Figueiredo e Grosfoguel (2009) optam por falar, então, em termos de uma distinção social entre mestiços mais claros e mestiços mais escuros.

3 Recusar o discurso ainda oficial e celebratório da mestiçagem não significa, evidentemente, defender uma lógica "segregacionista” ou de apartheid, mas antes apontar na direção de uma perspectiva ético-política antirracista capaz de analisar e intervir sobre a especificidade do racismo brasileiro. 
de reprodução da sociedade patriarcal e oligárquica local, antes através de um controle biopolítico das infinitas modulações dos fluxos de sangue que através de sua separação disciplinar, como no caso, por exemplo, dos estados do sul dos Estados Unidos ${ }^{4}$.

Autores como Schwarcz (1993) e Chalhoub (1996) apontam que as teorias raciais que circulavam na Europa e também nos Estados Unidos no final do século XIX foram reelaboradas no Brasil na mesma época de maneira original. O racismo científico brasileiro não deve ser, portanto, interpretado como apenas cópia ou imitação do racismo europeu, mas antes como tendo suas próprias idiossincrasias. A questão da mestiçagem sofre entre os séculos XIX e XX, sobretudo no período 1870-1930, uma série de transformações: antes apontada, de modo "pessimista”, como a causa da degeneração do povo brasileiro, no cenário do pós-Abolição, a mestiçagem começa a ser vista de forma mais “otimista” pelas novas teorias raciais de então, como mecanismo capaz de embranquecer e regenerar o “povo brasileiro”. Nesse cenário, o biopoder, o poder que incide sobre a vida da população, não mais se pauta por um mecanismo de negação do estatuto jurídico de cidadania dos negros - escravidão como sistema legal -, mas antes opera através de um corte "biológico” no interior da nova configuração da população brasileira. Trata-se de um momento histórico no qual a cidadania do contingente negro é formalizada e este passa a ocupar o "lado de dentro" da sociedade, os negros passam a ser parte constitutiva da população brasileira. É neste momento histórico que o discurso da miscigenação racial é apontado como saída para o “problema populacional” brasileiro (FLAUZINA, 2008). É neste sentido que a autora aponta a consolidação de um novo projeto de nação e que em sua esteira, uma série de providências é tomada para tornar essa população pura e sadia, apesar da "mácula da negritude" que estaria a impregná-la, na perspectiva do projeto racista em curso.

4 Mozart Linhares da Silva (p. 192), numa leitura biopolítica da miscigenação no Brasil, afirma que esta foi a base sobre a qual se articularam diferentes regimes de verdade que instituíram narrativas identitárias sobre a população como corpo-espécie em três diferentes momentos do século XX no Brasil: 1) "as primeiras décadas do século XX, período de efervescência da eugenia”; 2) “o período varguista, sobretudo o Estado Novo, quando a democracia racial fez da miscigenação uma estratégia identitária"; 3) "o contexto dos movimentos antirracistas diferencialistas, a partir dos anos 1980, quando o Movimento Negro ressignificou a ideia de raça e com ela a de miscigenação". Essa periodização é de fato muito interessante, mas aqui não me detenho na Era Vargas e prefiro indicar de maneira mais ampla o período de 1870-1930, como sugerido por Schwarcz (1993), para descrever as mudanças vividas nos discursos sobre a mestiçagem. 
A atuação estatal na produção da morte está inscrita nas diversas vulnerabilidades construídas em torno do segmento negro. A pauta do extermínio inaugurada no século XIX, intensificando-se com a proximidade da Abolição, será recepcionada na República dentro dessa nova metodologia. Assim, embalado na cantiga da democracia racial, o Estado, pela precarização da vida do contingente negro, foi construindo as condições para o descarte do segmento (FLAUZINA, 2008, p. 115).

Com efeito, no Brasil do século XIX, discursos impressos tornam visível a relação entre um "racismo contra o degenerado" e um racismo propriamente étnico-racial, pois constroem a figura da pessoa e da população negra como um mal biológico ${ }^{5}$. Esse momento de virada do século é bastante importante em termos de transformações na biopolítica na qual a população negra foi envolvida: fim do Império, Abolição da Escravidão, começo da República. Tais acontecimentos, bem como as práticas discursivas e não-discursivas a respeito da "raça" que então circulavam e se transformavam, têm papel fundamental na construção do que se entende por cidadania hoje no Brasil.

Em meio a um contexto caracterizado pelo enfraquecimento e final da escravidão, e pela realização de um novo projeto político para o país, as teorias raciais se apresentavam enquanto modelo teórico viável na justificação do complicado jogo de interesses que se montava. Para além dos problemas mais prementes relativos à substituição da mão de obra ou mesmo à conservação de uma hierarquia social bastante rígida, parecia ser preciso estabelecer critérios diferenciados de cidadania. (SCHWARCZ, 1993, p. 24, grifos meus)

Schwarcz explora a questão racial presente nos discursos, saberes e intervenções mobilizados em quatro tipos de instituição, criadas ainda no século XIX, que podem ser aqui pensadas como instituições fundadoras do Estado moderno brasileiro: 1) os museus etnográficos;2) os institutos históricos e geográficos; 3) as faculdades de direito; e 4) as faculdades de medicina. A autora explora a maneira original pela qual os "homens de sciencia" brasileiros - misto de cientistas e políticos, pesquisadores e literatos, acadêmicos e missionários - repensaram a questão do "atraso" e da "inviabilidade" da nação ressignificando a ideia de miscigenação. Com efeito, o “cruzamen-

5 Vera Malaguti Batista (2003) afirma que as preocupações em trono da supremacia étnica dos brancos em relação aos negros, seu medos em relação ao "equilíbrio populacional" entre brancos livres e africanos escravizados podem ser compreendidos em termos biopolíticos. Em sua pesquisa, a autora analisa uma série de publicações do século XIX que deixam à mostra nítidos "argumentos biopolíticos". 
to de raças" era, nesse momento de fins do século XIX, uma questão central para a compreensão dos destinos da nação. Estes cientistas tiveram de lidar com um problema preciso: aceitar a teoria da degeneração implicaria a confirmação da inviabilidade futura da nação brasileira, visto que o Brasil era percebido à época como uma nação já muito miscigenada ${ }^{6}$. Schwarcz indica, assim, a originalidade do pensamento racial brasileiro que, “em seu esforço de adaptação, atualizou o que combinava e descartou o que de certa forma era problemático para a construção de um argumento racial no país” (1993, p. 28) e afirma que “o pensamento racial europeu adotado no Brasil” foi aqui "introduzido de forma crítica e seletiva", transformando-se "em instrumento conservador e mesmo autoritário na definição de uma identidade nacional" e "no respaldo a hierarquias sociais já bastante cristalizadas" (1993, p. 55). Ela afirma ainda que o “saber sobre as raças” implicou “um diagnóstico sobre a submissão ou mesmo a possível eliminação das raças inferiores”, que, através da eugenia, pretendia intervir na reprodução das populações (SCHWARCZ, 1993, p. 78). Embora esta autora não desenvolva sua análise em termos de biopolítica, vê-se nitidamente o quanto se está nesse terreno aqui.

Ao elencar uma vasta sequência de materiais, Schwarcz evidencia o quanto que, a todo instante, se confirmam historicamente "imagens" absolutamente negativas do negro, este sempre ocupa o lugar mais baixo na hierarquia racial e social: "às populações negras restava a imagem da 'falta absoluta', mesmo quando se discutia a produção religiosa ou cultural" (SCHWARCZ, 1993, p. 152).

No Primeiro Congresso Brasileiro de Eugenia (1929),

o antropólogo Edgar Roquete-Pinto cumpriu um papel público importante, opondo-se à forte influência racista presente na maioria dos participantes do Congresso, que defendiam a aplicação de uma política eugenista radical e a teoria 'degeneracionista da mestiçagem'. [...] Roquete-Pinto sustentou o argumento de que o 'problema brasileiro seria uma questão de higiene e não de raça'(SCHWARCZ, 1993, p. 125).

6 Ao analisar a importância da teoria da degeneração ou degenerescência para a formação da psiquiatria brasileira, Vera Portocarrero (2002, p. 53) escreve: “A mestiçagem será considerada negativa para a composição de uma sociedade civilizada em que os padrões de progresso não devem ser ameaçados pela geração de indivíduos suscetíveis de degeneração física e moral, conseqüência da união de raças diferentes, que ao se cruzarem os transmitem à descendência, formando <raças mais fracas $>$.". 
Outro intelectual importante do período foi Silvio Romero. Mesmo tendo como pressuposto a ideia de que "ao elemento branco cabia um papel fundamental no processo civilizatório”, Romero,

em vez de lamentar a 'barbárie do indígena e a inépcia do negro', partia para soluções originais: estava na mestiçagem a saída ante a situação deteriorada do país e era sobre o mestiço - enquanto produto local, melhor adaptado ao meio - que recaíam as esperanças do autor (SCHWARCZ, 1993, p. 151).

Assim, no lugar da degeneração, começa-se a ver na mistura racial a própria viabilidade da nação, na qual as qualidades da raça branca, entendida como superior, predominariam sobre as raças negra e indígena, tidas como inferiores. A "solução original" dada pela intelectualidade brasileira do período 1870-1930 permanece, portanto, problemática, uma vez que o que está pressuposto em sua “imaginar a nação” é ainda uma lógica de embranquecimento "físico" e “cultural”, ou, pode-se dizer, um embranquecimento biopolítico.

\section{CONCLUSÕES POLÍTICAS PROVISÓRIAS}

A trajetória aqui reconstruída, de maneira breve e ainda incompleta neste texto, das questões do racismo e da mestiçagem como problemas biopolíticos só se tornou possível a partir de uma prática de colocação em xeque dos discursos oficiais elaborados pelo Estado brasileiro. Esta crítica e desconfiança em relação ao convívio entre a celebração formal da igualdade na lei, garantida pela Constituição - dita “Cidadã" - de 1988, e as desigualdades sociorraciais e violações de direitos que tocam sobretudo as populações brasileiras não-brancas se tornou possível graças a ação continua dos movimentos sociais negros no Brasil e no mundo. Trata-se aqui de questionar pressupostos tácitos, que colocam ainda hoje a "branquitude" como padrão intelectual, estético, discursivo, acadêmico, etc. Portanto, trata-se de reconhecer que a contribuição dos movimentos negros é a condição de possibilidade de uma leitura realmente crítica do racismo hoje e de questionamento de um regime de verdade que se pretende não-marcado - e por isso, um padrão pretensamente universal nas percepções de mundo -, aquele relacionado à manutenção da “cultura da branquitude" e do “prestígio branco”, da qual o próprio autor desse texto não está isento, nem mesmo no esforço de escrita do mesmo. 
Uma análise biopolítica do racismo colonial (ainda atual) brasileiro precisa, portanto, também passar pela crítica da “branquitude", episteme subjacente à boa parte do debate público sobre racismo no país. Concluo com uma citação de Abdias do Nascimento (1978, p. 93), um marco na história do pensamento brasileiro:

\begin{abstract}
A história não oficial do Brasil registra o longo e antigo genocídio que se vem perpetrando contra o afro-brasileiro. Monstruosa máquina ironicamente designada 'democracia racial' que só concede aos negros um único privilégio': aquele de se tornarem brancos, por dentro e por fora. A palavra - senha desse imperialismo da brancura, e do capitalismo que lhe é inerente, responde a apelidos bastardos como assimilação, aculturação, miscigenação; mas sabemos que embaixo da superfície teórica permanece intocada a crença na inferioridade do africano e seus descendentes.
\end{abstract}

\title{
REFERÊNCIAS
}

AGAMBEN, G. Homo Sacer: O poder soberano e a vida nua I. Belo Horizonte: Editora UFMG, 2010.

CHALHOUB, S. Cidade febril: cortiços e epidemias na Corte imperial. São Paulo: Companhia das Letras, 1996.

DA SILVA, M. L. Miscigenação e Biopolítica no Brasil. Revista Brasileira de História \& Ciências Sociais, São Leopoldo, vol. 4, n. 8, p. 192-210, dez/2012.

FIGUEIREDO, Â.; GROSFOGUEL, R. "Racismo à brasileira ou racismo sem racistas: colonialidade do poder e a negação do racismo no espaço universitário”. Soc. e Cult., Goiânia, v. 12, n. 2, p. 223-234, jul-dez/2009.

FLAUZINA, A. L. P. Corpo negro caído no chão: o sistema penal e o projeto genocida do Estado brasileiro. Rio de Janeiro: Contraponto, 2008.

FOUCAULT, M. Em defesa da sociedade: curso no Collège de France (1975-1976). São Paulo: Martins Fontes, 1999.

MALAGUTI BATISTA, V. O medo na cidade do Rio de Janeiro: dois tempos de uma história. Rio de Janeiro: Revan, 2003. 
MONTEIRO, S.; SANSONE, L. (orgs.). Etnicidade na América Latina: um debate sobre raça, saúde e direitos reprodutivos. Rio de Janeiro: Editora FIOCRUZ, 2004.

NASCIMENTO, Abdias do. O genocídio do negro brasileiro: processo de um racismo mascarado. Rio de Janeiro: Paz e Terra, 1978.

NEGRI, A.; COCCO, G. GloBAL: biopoder elutas em uma América Latina globalizada. Rio de Janeiro: Record, 2005 .

PORTOCARRERO, V. Arquivos da loucura: Juliano Moreira e a descontinuidade histórica da psiquiatria. Rio de Janeiro: Editora FIOCRUZ, 2002.

SCHWARCZ, L. M. O espetáculo das raças: cientistas, instituições e questão racial no Brasil -1870-1930. São Paulo: Companhia das Letras, 1993.

STOLER, A. L. La chair de l'empire: savoirs intimes et pouvoir raciaux en régime colonial. Paris: Éditions La Découverte, 2013. 